\title{
Article
}

\section{ORGANIZATIONAL CHANGE AND THE ANALYTIC THIRD: LOCATING AND ATTENDING TO UNCONSCIOUS ORGANIZATIONAL PSYCHODYNAMICS}

\section{Michael A Diamond}

Center for the Study of Organizational Change, University of Missouri-Columbia, Columbia, MO, USA

Correspondence: Dr Michael A Diamond, Center for the Study of Organizational Change, University of Missouri-Columbia, Columbia, MO 65211, USA

E-mail: Diamond@missouri.edu

\begin{abstract}
This article examines the concept of the analytic third in psychoanalysis and psychoanalytically informed organizational change. The analytic third is often defined as the psychological (triangular) space between self and other, subject and object, fantasy and reality - the third dimension that emerges from two persons fully engaged in the exploration of unconscious meanings, reasons, motives and actions. In neo-Kleinian object relations, it is viewed as the intersubjective dimension of transference and counter-transference, or the emergence in analytic work of the observation and experience of "I-as-subject" and "Me-as-object" (Ogden, 1994). The analytic third is what we create when we make genuine contact with one another at a deeper emotional level of experience whether in dyads, groups, communities, or organizations. It might be understood as akin to but not synonymous with Winnicott's (1971) notion of the transitional and potential space, where culture, play, creativity and imagination, reside. A case illustration is provided to better articulate the nature of the analytic third in the processes of observing, participating, and intervening in organizations.
\end{abstract}

\section{Keywords}

the third in psychoanalysis; the intersubjective field of awareness; triangular mental space; psychodynamics of organizational change; organizational identity

Psychoanalysis, Culture \& Society (2007) 12, 142-164.

doi:10.1057/palgrave.pcs.2100116 


\section{Introduction}

I suggest that the time has come for psychoanalytic theory to pay tribute to this third area, that of cultural experience which is a derivative of play. Psychotics insist on our knowing about it, and it is of great importance in our assessment of the lives rather than the health of human beings. (The other two areas are inner or personal psychic reality and the actual world with the individual living in it.) (D.W. Winnicott, 1971, p 102)

$\mathrm{U}$ nfolding the theory and practice of psychoanalytically informed organizational analysis and change requires a concept that captures the dialectical, experiential, and perceptual nature of working in depth with organizations. The third (or the analytic third) is such a penetrating analytic concept: one that accentuates the intersubjective dimension of the analyst's (researcher, consultant) position as a participant observer and witness of organizational culture.

\section{Introduction to the third in psychoanalysis and organizations}

Deep change in individuals and groups, as in psychoanalysis and psychotherapy, emerges out of reflective engagement and the dialectical nature of intra- and interpersonal processes. These interactive processes are comprised of creative and destructive tensions, regressive and progressive actions, paralysis and movement, social and psychological structures, conscious and unconscious motivations, and fantasy and reality. The tensions between these processes are experienced among leaders and followers, therapists and patients, consultants and clients, super- and subordinates, organizational participants, human systems and subsystems, subject and object, self and other. One can say that these social and psychological dynamics are the cognitive and emotional forces of human nature and relational systems - what Winnicott (1971, p 102) refers to above as "the actual world with the individual living it."

Regardless of whether we call these forces of human nature dialectical tensions, paradoxes, splits and fragments, or simply conflicts, one observes the emergence of a third dimension or mode of experience, and it is in this intermediate area that things actually happen, and it is within this psychological space that the deeper work of organizational analysis and change occurs. In this paper, I address the concept of the analytic third (Ogden, 1994) or the third (also referred to as thirdness, triangular space, and the third subject) in contemporary (two-person) object relational psychoanalysis (Winnicott, 1971; Lacan, 1975; Ogden, 1994, 2004; Cavell, 1998; Mitchell and Aron, 1999; Benjamin, 2004; Britton, 2004; Gerson, 2004; Green, 2004; Minolli and Tricoli, 2004; Zweibel, 2004). I suggest that the psychoanalytic concept of the third represents the focal point for studying and attending to unconscious 
organizational psychodynamics; it is the location and mental space for witnessing and intervening in reflexive individual and group processes. It is my purpose here to call attention to the "triangular space" where we observe, analyze, and consult human relations in organizations - the analytic third. In this spirit, the third may be described as a "position" the analyst takes up, or, paradoxically it might be viewed as "a place without a place" (Britton, 2004; Zweibel, 2004, pp 235-236) as in the notion of psychic reality.

In what follows, I plan to discuss the varied ways in which the third in psychoanalysis is defined. Most of my sources on the subject come from a special issue on "The Third in Psychoanalysis" in the Psychoanalytic Quarterly (Volume LXXIII, Number 1, 2004). This special issue is quite remarkable in its attempt to promote a dialogue between relational, Kleinian, neo-Kleinian, and other analysts on the topic of the third. As with many important concepts in psychoanalysis, the third is frequently defined differently by theorists, clinicians, and practitioners of multiple schools of psychoanalytic thought. My review is not exhaustive. Yet, it is an attempt to illustrate without perpetuating more confusion the multiple ways in which one can consider the value of the third in psychoanalysis and psychoanalytic organizational practice. Next, I propose how we might conceptualize the third in the psychoanalytic approach to organizational analysis and change. Finally, a case vignette is provided to better articulate the nature of the analytic third in the processes of participating and observing, analyzing, and intervening in organizations. I preface my review of the literature on the third with some articulation of my own position, which I return to in the vignette and my discussion of the third in psychoanalytic organizational consultation.

\section{The concept of the third in psychoanalysis}

The third in psychoanalysis stems from an acknowledgement among theorists and practitioners of the value of reflective action, participant observation, and the nature of dialectical, intersubjective processes in object relations. It is also consistent with the value placed on transference and counter-transference, and the self-consciousness of the analyst and his or her capacity to use the self as an instrument of observation. The introduction of the concept of the third signifies a change in the psychoanalytic paradigm as well from one- to two-person psychology, and more recently the emphasis among relational psychoanalysts on intersubjectivity - the intersubjective third subject.

The purpose of a "two-person psychology" is to emphasize the emergence of what Ogden calls "the intersubjective analytic third." These emergent properties of the dyad exist in dialectical relation to the individual subjectivities of the patient and the analyst. (Mitchell and Aron, 1999, $\mathrm{p} X \mathrm{XV}$ 
In my experience, the analytic third is where the productive work of repairing and integrating fragmented and broken human systems occurs. Thirdness materializes when two persons are fully engaged in the exploration of unconscious meanings, reasons, motives, and actions. In the history of psychoanalysis, this notion of the production of a third subject surfaces most prominently with the paradigmatic shift from the classical drive model to the contemporary relational model - a transition from focusing on instincts to relationships. The former is more preoccupied with intra-psychic structure and the psychodynamics of tension reduction, while the latter is more encompassing of intra- and intersubjectivity and object-seeking motivations. The intersubjective third is apparent in the phenomena of transference and countertransference, and projective identification - the emotional bonds, or knots, that tie one to another, which, in their unconscious form, Thomas Ogden (1994) calls the subjugating third.

I begin this exploration with some clarification of my own position on the third in psychoanalysis and organizations. I am particularly focused on its application in the "here and now" of psychoanalytic organizational interventions. In my view the analytic third is established when we make genuine contact with one another at a deeper emotional level of experience, whether in dyads, groups, communities, or organizations. In individuals, groups, and organizations, the third is the location of mutual understanding and recognition between two or more subjects. It is also a position that transcends the individual and the dyad, which is precisely why it has such relevance for organizational work. As cooperative systems, organizational participants require consciousness of mutuality, shared identity, and complex relational systems. The psychoanalytic notion of the third illuminates the dual position of participation and observation, which, as Britton (2004) points out (in his reference to the work of philosopher John Searle (1995)), comprises ontological subjectivity and ontological objectivity. Thus, the concept of the analytic third (or, in Britton's term, triangular space) enriches our understanding of the psychological processes necessary to produce self, group, and organizational consciousness and reflectivity.

In organizational analysis, as will be evidenced in the case example and descriptions of organizational diagnosis and change presented later in this article, the psychodynamic processes between consultant/analyst and client system share much in common with object relational approaches to psychoanalysis and psychotherapy. In particular, the approach presented here reflects the analytic practice of moving back and forth between subjective (first person) and objective (third person), or between the role of Oedipal provider of the law ("This is how it is, you need to face up to it") and that of the more containing partner in a process of mutual recognition and creation (Searle, 1995; Britton, 2004). ${ }^{1}$

The present review of the concept of the third in psychoanalysis includes the contributions of Winnicott, Benjamin, Britton, Ogden, Minolli and Tricoli, 
Table 1 The third in psychoanalytic theory

\begin{tabular}{|c|c|}
\hline $\begin{array}{l}\text { Winnicott's third as transitional } \\
\text { and potential space }\end{array}$ & $\begin{array}{ll} & \text { Intermediate area } \\
- & \text { Culture } \\
- & \text { Psychic reality (experiential) }\end{array}$ \\
\hline Benjamin's thirdness & $\begin{array}{l}\text { - Intersubjectivity and mutual recognition } \\
\text { - Attending to dominance and submission } \\
\text { - Creating relational systems }\end{array}$ \\
\hline Ogden's analytic third & $\begin{array}{l}\text { - Intersubjective third subject } \\
\text { - Subjugating third (projective } \\
\text { identification) }\end{array}$ \\
\hline Britton's triangular space & $\begin{array}{l}\text { - Closure of the Oedipal triangle } \\
\text { - Limiting boundary for the internal world } \\
\text { - Third position as observer and witness }\end{array}$ \\
\hline Minolli's and Tricoli's Hegelian third & $\begin{array}{l}\text { - Solving the problem of duality } \\
\text { - Third as self-consciousness }\end{array}$ \\
\hline $\begin{array}{l}\text { Gerson's third as the relational } \\
\text { unconscious }\end{array}$ & $\begin{array}{l}\text { - Developmental third } \\
\text { - Cultural third } \\
\text { - Relational third }\end{array}$ \\
\hline $\begin{array}{l}\text { Green's concept of the third in } \\
\text { psychoanalysis }\end{array}$ & $\begin{array}{l}\text { - Binding, unbinding, and rebinding } \\
\text { - Rebinding as third element }\end{array}$ \\
\hline
\end{tabular}

Gerson, and Green. Table 1 is provided as a summary orientation of their contributions, which may help the reader to better differentiate and compare the substantive contributions of each.

In developing the concept of the third for organizational analysis and change, I begin with a brief review of Winnicott's notion of transitional and potential space.

\section{Winnicott's third as transitional and potential space}

The concept of analytic third shares much in common with Winnicott's (1971) notion of the transitional and potential space, the intermediate area where culture, play, creativity and imagination reside. Winnicott introduces the concept of potential space in Playing and Reality:

I put forward for discussion of its value as an idea the thesis that for creative playing and for cultural experience, including its most sophisticated development, the position is the potential space between the baby and the mother. I refer to the hypothetical area that exists (but cannot exist) between the baby and the object (mother or part of mother) during the phase of the 
repudiation of the object as not-me, that is, at the end of being merged in with the object. (1971, p 107)

So it would seem for Winnicott the emergence of potential space via playing and cultural experience coincides with the baby's earliest acknowledgment of itself as separate from yet attached to the mothering one. And, it would seem to be the case that the creation of this transitional space or intermediate area of experience, as Winnicott called it, requires some sense of confidence, safety, and security in the presence, empathic attunement, and nurturing capacity of the mothering one. Potential space then originates with the infant's experience of responsive mirroring and maternal affection grounded in good enough mothering (or good enough holding environment), where the baby develops the capacity to be alone and the curiosity to explore his or her internal and external world $(1965,1971)$.

For Winnicott, the potential space is where we (adults and children) live and experience living, neither in fantasy nor reality but somewhere between the two. It is essential to maturation and the emerging sense of self. The notion of potential space is at the heart of Winnicott's thinking, what Ogden (1994) calls Winnicott's intersubjective subject. However, it ought to be noted here (as is the case with others) that Winnicott's third is incomplete and therefore limited in ways that will become evident with the additional views presented below. Suffice to say that Winnicott's third as transitional and potential space is a dimension of the analytic third in which the consultant/analyst provides containment and fosters innovation and creativity in setting and solving problems. Consultants do become transitional objects for their clients in the process of shifting an organizational culture from an unconscious state of defensive denial and fantasy to one of consciousness and attunement to social and political realities.

Winnicott's revisions of Kleinian object-relations theory and, in particular, his concepts of potential and transitional space, have influenced a contemporary generation of psychoanalysts and psychoanalytic writers. Benjamin's concepts of thirdness and intersubjectivity, for example, add to a deeper understanding of the psychodynamics of organizational hierarchy, power, and authority, by highlighting the sadomasochistic interplay of dominance and submission between supervisors and subordinates, executive managers, and workers.

\section{Benjamin's concept of thirdness and intersubjectivity}

In "Beyond Doer and Done To: An Intersubjective View of Thirdness," Jessica Benjamin (2004) states: "thirdness is about how we build relational systems and how we develop the intersubjective capacities for such co-creation." Thirdness is a quality or experience of intersubjective relatedness akin to Winnicott's "potential space," or his "transitional space" (p 7). The third is not a "thing" but a "principle, function, or relationship" (p 7). "In the space of thirdness, we are 
not 'holding onto' a third; we are, in Ghent's (1990) felicitous usage, surrendering to it" (p 8).

The third is then that to which we surrender, and thirdness is the intersubjective mental space that facilitates or results from surrender. This non-defensive act of surrender does not refer to submission or compliance; rather it refers to a certain letting go of the self, and thus implies, as Benjamin and Ghent suggest, the ability to take in the other's point of view or reality. "Thus, surrender refers us to recognition - being able to sustain connectedness to the other's mind while accepting his separateness and difference: Surrender implies freedom from any intent to control or coerce" ( $p$ 8). According to Benjamin, thirdness is that intersubjective mental space that emerges from our capacity to surrender - in the sense of opening up one's intersubjective field of awareness and opening up to the emergence of the co-constructed third subject. ${ }^{2}$

We can attend to constructive and destructive, liberating and oppressive relational systems by surrendering to the recognition of mutual subjectivities discovered in the third. Benjamin is acutely aware of the challenges of the oppositional nature of two subjectivities and their separate realities, particularly as it relates to Hegel's master-slave and the relational dynamics of masochism and sadism, dominance and submission. She writes "the presence of an observing third is felt to be intolerable or persecutory" ( $p$ 30). The subject may experience the occupying force of the object; unconscious sabotage and collusion may be present. Under such circumstances, the boundaries between "me and you" become confused and inadequately delineated inside the mush of transference and counter-transference, projection and introjection. Benjamin states: “... malignant complementarity takes hold, the ping-pong of projective identification - the exchange of blame - is often too rapid to halt or even obscure" ( $p$ 30). Benjamin's notion of thirdness enables analysts, via their awareness of the transference trap, to untie the emotional knot and thereby enhance their understanding of their own participation in the co-constructed relational system. Similarly, Ogden's position on the analytic third stresses the value of consciousness around projective identification and what he calls the "subjugating third" in transference and counter-transference.

\section{Ogden's analytic and subjugating third: attending to projective identification}

The analytic third, according to Ogden (2004), refers to a third subject unconsciously co-created by analyst and patient, "which seems to take on a life of its own in the interpersonal field between them" (p 169). This third subject stands in dialectical tension with the separate individual subjectivities of analyst and patient in such a way that the individual subjectivities and the third create, negate, and preserve one another ( $\mathrm{p}$ 189). The third subject (or thirdness) is the product of the dialectical processes of the relational unconscious. We confirm, 
disconfirm, and reconfirm each other in the sense of mutual recognition of our individual subjectivities. The analytic third signifies the analyst's position and consciousness of the intersubjective subject or co-created third. ${ }^{3}$

Thus, our simultaneous surrendering to, and awareness of, the third position ${ }^{4}$ enables us to attend to (without being entrapped by) coercive and collusive relational psychodynamics such as projective identification. ${ }^{5}$ Ogden refers to this dimension of the third as mutual subjugation in contrast with mutual recognition (2004, p 187). He adds that the analytic third comprises a tension between mutual subjugation and mutual recognition. That is, if the relational processes of projective identification inherent in the dynamics of mutual subjugation between analyst and patient, consultant and client, become conscious, recognized, and attended to, then the analyst is in a position to locate him- or herself in the analytic third. The analytic third is the mental space for insight and change. It is also the analytic space for working-through resistances to insight and change. And, if there is any possibility of deconstructing the twisted and misplaced relational dynamics under the influence of projective identification, then it would seem to be more probable from the vantage point of the analytic third.

Figure 1 illustrates that analytic third as a position, the intersubjective subject, taken up by the participant-observer (organizational analyst/consultant). It reflects the location and mental space of reflexive individual and group processes where one participates, observes, witnesses, analyzes, and consults organizational members. Its focus is on dialectical, intersubjective dynamics at the apex of the triangle. From this position one experiences, observes, and articulates the collision and potential collusion of psychological forces between subject and object, including such coercive relational dynamics as projective identification.

Consciousness of the analytic third and that which is co-created between two or more individual subjectivities in a relational system enables us to observe and attend to the emotional whirlwind of transference and counter-transference dynamics - the shared emotions of individual and mutual subjectivities. In the midst of a fury of projected and introjected emotions, the theory of the analytic third is a process and potential space from which to articulate and differentiate self and other, me and you, container and contained. ${ }^{6}$

Ogden explains how projective identification operates in the space of the analytic third:

The interpersonal facet of projective identification - as I view it from the perspective generated by the concept of the analytic third - involves a transformation of the subjectivity of the "recipient" in such a way that the separate "I-ness" of the other-as-subject is (for a time and to a degree) subverted. In this unconscious interplay of subjectivities, "you [the 'recipient' of the projective identification] are me [the projector] to the extent that I need 


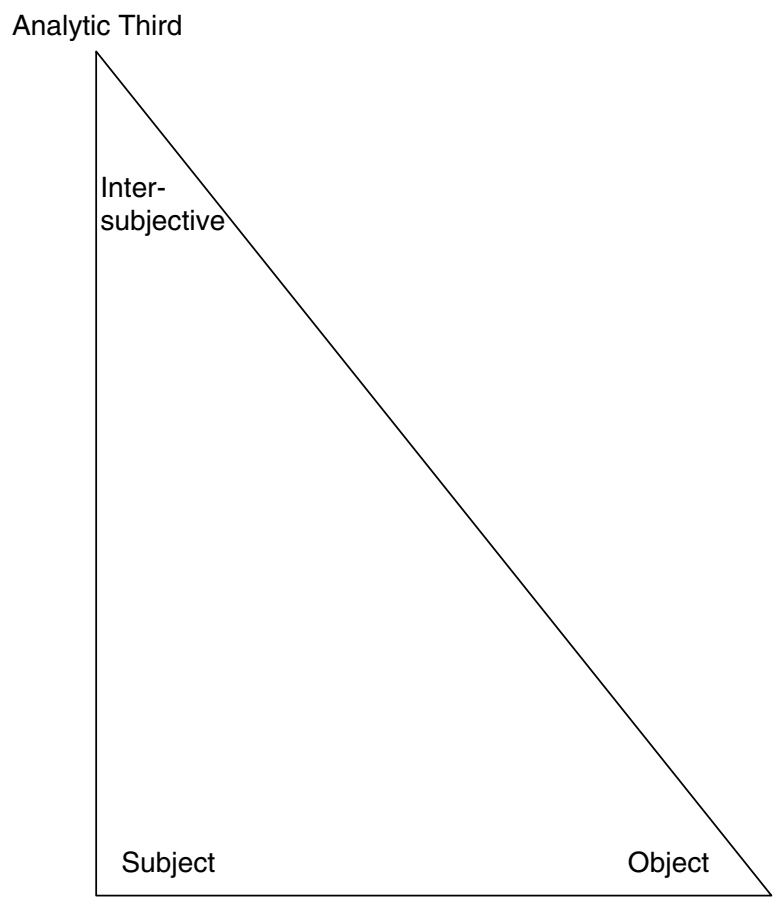

Figure 1 The analytic third as triangular mental space for reflectivity and change.

to make use of you for the purpose of experiencing through you what I cannot experience myself. (Ogden, 2004, p 188)

Ogden describes the recipient in the subjugated analytic third of projective identification as metaphorically making "psychological room" for the projector's temporary occupation. The projector turns him- or herself over to the recipient and in effect transfers the disavowed unconscious (part self-object) to the outside other. The recipient then participates, according to Ogden, in a negation of oneself by surrendering to the "disavowed aspect of the subjectivity of the projector" ( $p$ 189). Thus, the recipient is able to open up his or her interpersonal field of experience (mental space) between the two subjectivities (self and other). It is then from the vantage point of the initially subjugated third that the recipient attempts to process and comprehend (via identification and recognition) the other's subjectivity as separate from yet linked with his own.

In much the same way as Bion's (1967) notion of container and contained is operational in the therapeutic encounter, the analytic third signifies the psychodynamic processes in which the recipient eventually verbalizes and affectively returns to the projector his disavowed subjectivity and in a form the projector can receive, reclaim, and find meaningful. Thus, from the position of 
the analytic third, the projector makes use of the recipient as a container of toxic and non-toxic emotions. In the process of reclaiming split-off and evacuated parts of oneself, self-cohesion is enhanced, along with the capacity to distinguish sensations of "me and not-me." A more unified sense of self comprised of good and bad parts is derived from the psychodynamics of an expanding mental space, or thirdness. ${ }^{7}$ This expansion of mental space is precisely what Britton attempts to describe in his notion of the third as "triangular space" rooted in early oedipal relations.

\section{Britton's subjectivity, objectivity, and triangular space}

Similar to Ogden, Britton's perspective of the third rests on the work of Melanie Klein and W.R. Bion. However, his explicit emphasis on Klein's concept of the early oedipal relations and Bion's theory of containment somewhat differentiates Britton's approach. His concept of the third provides a fuller and more appropriately nuanced view of the application of the third in psychoanalysis and, by my own extension, in organizations. His focus on "malignant misunderstanding" in narcissistic and borderline conditions extends Benjamin's exploration of the psychodynamics of dominance and submission, and the invisibility of the other. It also enhances our understanding of Ogden's subjugating third and the collusive and manipulative psychodynamics of "projective identification." In describing the early oedipal triangle Britton writes:

The acknowledgement by the child of the parents' relationship with each other unites his psychic world, limiting it to one world shared with his two parents in which different object relationships can exist. The closure of the oedipal triangle by the recognition of the link joining the parents provides a limiting boundary for the internal world. It creates what I call a "triangular space," i.e., a space bounded by the three persons of the oedipal situation and all their potential relationships. It includes, therefore, the possibility of being a participant in a relationship and observed by a third person as well as being an observer of a relationship between two people. (2004, p 47)

Britton's application of Klein's theory of early oedipal relations and Bion's theory of containment are present in this quote and throughout his work. For our purposes, it is valuable to point out that the relative success for the individual of negotiating the early oedipal triangle is in part dependent upon the internalization of appropriately limited ego or self-other boundaries. This outcome of self-integrity (integration) is derived from good enough holding or maternal containment. And, as Britton and Searle (1995) point out, the third person (objectivity) emerges as one who is no longer simply a participant (first person, subjectivity); rather, one becomes a witness (third position) as well. So, too, the organizational analyst moves back and forth between what Searle calls 
ontological subjectivity and ontological objectivity, between organizational diagnoses and containing interventions. The third position as described by Britton, Benjamin, and Ogden assumes a Hegelian self-consciousness as well as a cognitive and emotional grasp of relational complexities - paradoxical and dialectical. In this spirit, Minolli and Tricoli view the concept of the third as a solution to the problem of duality.

\section{Minolli and Tricoli's Hegelian third as solution to the problems of duality}

Much like Ogden's notion of "making psychological room" for the other, for Minolli and Tricoli (2004) this expansion of mental space or thirdness comes along with the development of Hegelian (1807) self-consciousness. In their discussion of the concept of the third in psychoanalysis, they remind us that new concepts emerge in the history of ideas when a problem exists that needs to be solved, and according to the authors, psychoanalysis has come up with the concept of the third to solve the problems of duality. Writing on the evolution of psychoanalysis, the authors suggest: "We think that the third was born as an attempt to recall the human being's capacity to grasp [oneself] reflexively. This belief is confirmed by the increasingly widespread use of terms like 'reflexive function' or 'metacognition' (Fonagy et al., 1991), 'reflexivity' (Mitchell, 1988), 'self-reflexivity' (Aron, 1998), and many others in psychoanalytic literature" (p 143). The authors further illuminate our understanding of the third and its function in psychoanalysis by reintroducing the Hegelian (1807) concept of selfconsciousness from the philosopher's descriptions of the phenomenology of consciousness in The Phenomenology of Mind. ${ }^{8}$

The notion of the third as self-consciousness represents a mental space or position from which one can see and experience the binding and ego distorting affect of projective identification, transference and countertransference, relational dynamics. The intersubjective third provides the self (or ego) with a metaphorical, observational, lift (much like a ski lift), and thus a vantage point from which one can view the landscape of the relational unconscious dynamics. In Hegelian philosophy, perception, intellect, and self-consciousness are the three levels of consciousness, where perception and intellect are developmental precursors to self-consciousness (Mills, 2000). Minolli and Tricoli write that "for Hegel (1807) development of consciousness takes place through the 'forms' (Gestalten) of perception, intellect, and selfconsciousness" (p 143). ${ }^{9}$

Perception and intellect are forms of consciousness derived from the subject's infantile dependence on the object. So the primitive and emergent self is in part temporarily located inside the object - as in the form of projective identification. Self-consciousness develops along with overcoming dependence on the object. In other words, self-consciousness emerges out 
of the developmental transition from total dependency to relative autonomy as described by object relations theorists such as Fairbairn (1952), Guntrip (1969), and Winnicott (1971). It is currently understood from infant research (Stern, 1985), for example, that the sense of self as "I-subject" occurs around 18 months of age, at the time the child has the capacity to carry internalized object representations (pp 144-145). Hence, "me and not-me" sensations become better delineated along with the subject's rather primitive sense of subjectivity. At this juncture it might be said that the nascent form of a developmental, cultural, and relational third takes shape.

\section{Gerson's third and the relational unconscious}

In his article "The Relational Unconscious: A Core Element of Intersubjectivity, Thirdness, and Clinical Process," Gerson (2004) identifies three different experiential dimensions of thirdness. First, he refers to the developmental third, which is a position that invokes an oedipal constellation. The oedipal constellation, according to Gerson, represents a third entity (person, institution, or symbol) that disrupts the dyadic. The third subject interferes with the emotional bond between subject and object. Second, the cultural third is a nonintersubjective form of thirdness, according to Gerson, which does not arise from the subjectivities of the individuals in the dyad, but rather "envelops, intrudes upon, and shapes the interactions of the dyad, as well as the subjectivities of each member of the dyad. Exemplars of the cultural third are such forces as the incest taboo, language, and professional standards ..., with each representing a codification, both legal and semiotic (Pierce, 1972), of the possible and the prohibited" (p 77).

Finally, the relational third for Gerson is the notion of thirdness that arises from within the dyad and stems from intersubjectivity or the combination of individual subjectivities. In other words, the relational third comprises the collision of subjectivities and the dialectical processes of negation and affirmation. Gerson writes: "the relational unconscious is not an object, a third, a triad, a field, or a space. Each of these renderings connotes - even if it is not the intention of the author to do so - an entity that can be separated from the two subjectivities that combine to create it. Intersubjectivity and the relational unconscious are better thought of as processes through which individuals communicate with each other without awareness about their wishes and fears, and in so doing, structure the relation according to both mutually regulated concealments and searches for recognition and expression of their individual subjectivities" ( $\mathrm{p}$ 81). The relational unconscious is structured out of the developmental processes of separation and individuation, or what Andre Green (2004) describes as binding, unbinding, and rebinding. 


\section{Green's concept of the third element: Binding, unbinding, and rebinding}

In his paper on thirdness, Green (2004) refers to the psychodynamics of binding, unbinding, and rebinding. Binding and unbinding signify respectively the dynamics of attachment and separation, or as Green prefers, Freud's notion of life and love instincts on the one hand, and destructive instincts on the other; rebinding stands for the reunion or reuniting of two parts (part-objects) of a broken unity. Rebinding is the third element, according to Green, which refers to reunion after separation. "In symbolization, two parts of a broken unity are reunited; and the overall result can be considered not only as the rebuilding of a lost unity, but also as the creation of a third element that is distinct from the other two split-off parts" (p 107).

Binding, unbinding, and rebinding seem analogous to processes of attachment, separation, and loss in attachment theory and object relations theory (Bowlby, 1969, 1973, 1980; Fonagy, 2001). As I see it, the third element of rebinding is descriptive of the psychodynamics of change in the depressive position, and the notion of change as emotional loss and eventual reparation (Klein and Riviere, 1964; Klein, 1986).

Rebinding is a reparative and re-integrative process. Profound change, individual and organizational, engages the analytic third of analysts and participants alike in constructing, de-constructing, and re-constructing the intellectual, perceptual, and emotional bonds between self and other, subject and object. Table 2 is my attempt to summarize the relevance of the analytic third for psychoanalytically informed organizational change and consultation.

\section{Thirdness as an emerging organizational identity}

In organizational consultation, these depressive and reparative processes include grief and mourning as a natural yet often overlooked component of change. In reflective work groups, the psychodynamics of grief include denial, anger, aggression, resistance, disorganization, re-integration, and reorganization. Object loss permeates the transitional space (Diamond et al., 2004). The psychodynamics of binding, unbinding, and rebinding foster reuniting broken or fragmented parts of relational systems of people, roles, and organization. These transitional processes signify a shift from paranoid-schizoid modes of experience (where splitting and projective identification abound) to depressive ones (where mutual recognition and reparation are possible). As evidenced in the case vignette to follow, the concept of the third here refers to an awareness of an emerging triangular space and organizational identity. This stems from the provision of oedipal law in the presentation of the organizational diagnosis and from the consultants' containment of the client system - a good enough holding environment. The consequence of deep listening, trust-building, and empathic 
Table 2 The analytic third in psychoanalytically informed organizational consultation

Reflective inquiry about

- Dialectical tensions

Subjectivity $v s$ objectivity

Social $v s$ psychological structures

Group $v s$ individual

Fragmentation $v s$ integration

Dominance $v s$ submission in role

Change $v s$ resistance to insight and change

- Third as location of organizational identity and change processes

- Triangular space and the organization-in-mind

- Psychic reality and the subjugating third (experience, transference and counter-transference, splitting and projective identification)

- From paranoid-schizoid toward depressive modes of experience

- From fragmenting toward integrative processes

- Change as emotional loss (grief and mourning as reparative processes)

understanding in the process of organizational diagnosis (through participation, observation, and structured interviewing) provides the client with an interpretation (assessment) and a container for unconscious and previously unarticulated emotions and anxieties.

This triangular (or potential) space is the intermediate area of colliding subjects and objects, roles, and divisions. The organizational identity (or emerging organizational image) is the third subject surfacing above the dyad, solving the problem of duality, as we engage participants in reflective inquiry. The third position signifies participants' capacity to occupy the mental space of observation, reflexivity, and double loop learning (see Argyris and Schon, 1978), which enables clients to produce alternative relational structures and more meaningful, productive, and humane organizations.

In sum, during the course of organizational interventions, analysts (consultants) articulate the third subject, organizational identity, through participant observations linking "here-and-now" interactions with those of the organization and its collective past. The analytic third is attended to by consultants' efforts to enhance the members' capacity for reflective action (reflexivity) and insight for genuine relational change, and gathering the fruits of these efforts requires our intervening in the psychodynamic processes of human relations at work.

\section{Organizational change and the analytic third}

In organizational change, the analytic third is that triangular space comprising the relational system, which is opened up between people and their organization, between individuals and their roles and responsibilities, between units, 
divisions, professionals, specialists, and disciplines. Locating and attending to this in-between area (or surface of the boundary) is essential in repairing fragmented relationships and linkages between groups and divisions inside organizations. The organizational analyst facilitates the dialogue in the change process at the moment participants seem open to suspending often long held assumptions and beliefs about themselves and their roles in the organization. Typically this occurs following the analysis of resistance to change and a minimization of defensiveness characterized by greater openness to learning from each other (as illustrated in the vignette below).

In sum, the analytic third emerges at the time participants become fully engaged with each other and their consultants in a reflective process of self and other examination - a third position from which it becomes plausible to acknowledge and reclaim projected emotions and attributions.

\section{Case vignette: the analytic third in organizational consultation}

Several years ago I worked with a department of psychiatry (I have changed both the kind of organization and certain facts so that the clients' anonymity and confidentiality are protected). Along with a female associate, I provided a comprehensive organizational consultation to a department described by its executive and several executive team members as riddled with deeply personal and frequently vicious interpersonal conflicts. Often, when they met as a group to discuss department business or to engage in intellectual, theoretical, and clinical discourse, which included individual case presentations, their differences and disagreements escalated into hostilities. The leadership and department membership were unable to tolerate or contain discord among them. Consequently, meetings would frequently end with members destructively personalizing their differences and further fragmenting the department itself into ideological and embattled camps and unproductive divisions.

The turmoil among members and the frequent dysfunction worried them greatly as they needed to engage the department in serious strategic and business planning. Many knew it was time to reexamine their mission, goals, and strategies in order to turn around decreasing student enrollments, diminishing patient populations for psychotherapy, and depleted institutional morale. Political and economic conditions in health care and the impact of managed care made reimbursement more difficult and discouraged many medical students from specializing in psychiatry. Those who did were discouraged from practicing psychotherapy for economic reasons as well. The department head and her executive team of administrators and clinicians felt something needed to be done; they needed more effective strategies to adapt to an unwelcoming political environment. Yet, they could not accomplish anything of this magnitude until conflicts from within were reconciled and until they had 
developed the capacity to work more effectively as a team and with a stronger sense of affiliation to the department.

The consultants provided the Department of Psychiatry with a structured method and process for assessment (organizational diagnosis), feedback, and strategic interventions. After several weeks of on-site interviews and data collection, the organizational analysts (consultants) presented the department with a depiction of the organization. It was during this time, space, and experience of telling the organizational story and offering it to the clients as a representation of their collective identity (organizational identity) that a glimmer of thirdness in the group emerged in a climate of otherwise injured narcissism, broken and distorted relationships.

The department members gathered to hear and see before them their narrative - the story derived from the factual, historical, and narrative data of structured interviews, observations, participation in groups and committees. The organizational text was projected onto a flip chart and the consultants (male and female) read from the text of their organizational diagnosis. In the spirit of a provision of the oedipal law and the establishment of triangular space, the organizational analysts were saying to their clients: "Here it is. This is our best depiction of who you are as an organization based on what we experienced, observed, and heard from all of you." Sometimes, at this point in the consultation, the organizational analyst can feel people in the group shift their attention off themselves, momentarily, and onto a larger and more systemic image of themselves, an image that signifies "you are more than any one individual in this room, you are a group, an organization, yet all of you share responsibility for your culture and for your collective identity." With this in mind department members temporarily shifted their attention and expanded their perspectives away from this preoccupation with internal fragmentation, angst and interpersonal conflicts, and toward seeing themselves as a group and as an organization, not simply a collection of individual clinicians and administrators.

In this particular case, it was as if, in the course of the dialogue and our facilitation of transitional and potential space (the analytic third), members for a short time transcended their own narcissism and their proclivity to be entrapped in dyadic relations. Thus they could move beyond their obsession with interpersonal conflicts - the third as solution to the problem of duality. It seemed that by focusing on themselves as a group and organization, they momentarily broke down their own resistances to the process of psychodynamic organizational consultation and their resistances rooted in the belief that the consultants could not change anything since they "could not change members' personalities."

The telling of the organizational story altered group members' awareness of their particular gestalt. Their attention moved away from themselves as individuals and dyads. They seemed to overcome at least for the time being their 
investment in interpersonal conflicts and psychological splitting into groups of enemies and allies. Rather, they came to see themselves via the analytic third as comprising a whole system - an organizational identity. With intensive, reflective, and repetitive group sessions, movement from relational binding to unbinding, and ultimately to rebinding occurred, from which point broken unity in the group could lead to re-unity and reparation. However short-lived it might have been, part object relationships within the group became more characteristic of whole object relations and the capacity to acknowledge, tolerate, and value similarities as well as differences among members.

Finally, one incident late in the consultation depicted the value and function of the analytic third and the quality of thirdness for the consultant and participants. Sabotage is not unusual in organizational change efforts and late in the consultation one member introduced a letter to the group. In the letter the author, a member of the department not present in the group at the time, had written a vicious criticism and personal attack on a colleague who was at that time present in the group. The purloined letter was shared openly by a protective female colleague. In response, group members got angry, felt shame, regressed and retreated into pre-existing oppositional camps. Some defended the perceived victim of the attack, while others attacked the messenger for bringing it out into the public without the author's permission or knowledge. The group collapsed into familiar paranoid and schizoid dynamics. The consultants called for 10-minute break (a needed "time-out") in order to assess and process what was going on. At the break several members aggressively lobbied the consultants as "judges" and defenders of the oedipal law to "deal with" the incriminating letter and the "malicious and cruel person who wrote it." It was as if these members were demanding justice (in the author's absence) and that the consultants were somehow in a position to proffer justice and determine punishment (consultants are often viewed unconsciously, if not consciously, as judges). Psychological splitting and projected aggression in the group reinforced scapegoating among several members.

We then reconvened the group and reminded them of their task as a group. I suggested that what was going on was indicative of the patterns and themes inherent in their organizational story - we had just witnessed an enactment. I continued by suggesting that they now had an opportunity to acknowledge it as a painful and unfortunate critical incident symbolic of their organizational identity - assuming responsibility for their actions. Once they could acknowledge it as part of their collective past, they could move forward in a productive and progressive manner. Here we were giving the group in the midst of sadomasochistic and paranoid-schizoid dynamics an opportunity to reflect on themselves and assume responsibility for themselves as a group and organization. We also provided them with an opportunity to reflect on what had just happened in the group as evidence of and confirmation for the organizational diagnosis. Consequently, they were able to see how the introduction of the letter 
and their reaction to it perpetuated vicious fragmentation and aggression reminiscent of their addiction to group regression and paranoia, which in the past had rendered them dysfunctional as an organization. They could see how this incident signified their tendency as a group to move into and remain stuck in a fragmented and broken state.

For the consultants and ultimately the clients, focus on the analytic third signified movement into a triangular (potential) space where they could engage in reflective inquiry and participant observation, enabling them to acknowledge their regressive group processes and their own impact on themselves as an organization - the third as consciousness of organizational identity. It was as if the consultants were asking clients to join them at the apex of the triangle (illustrated in Figure 1 above). Then with that awareness and desire to move forward, developing members' capacity to acknowledge entrenched narcissistic injury and the subjugating third of projective identification (as represented by the letter and its author's and messenger's unconscious intent), they could return to the task at hand. They could now begin to see themselves as a work group with a mission and goals, the result of their emergent organizational third.

Several clients unwittingly distorted and confused psychological boundaries between themselves and the consultants by demanding affirmation and indulgence in the psychodrama playing out in the group, while process consultation required that the analysts acknowledge, contain, and modulate the splitting and aggression belonging collectively to the clients. Consultants may take the emotional bait from time-to-time in organizational consultation; thus, it is important that analysts nurture their collective analytic third and nurture their ability to enhance participant-observation and reflectivity through reflective processing of their work with clients and with routine debriefing.

\section{Organizational diagnosis and the production of the third subject}

The case vignette illustrates a key element of organizational change and intervention: organizational diagnosis, once complete, is presented publicly to all the participant subjects in the form of an organizational story. This narrative process represents the production of a third subject, the organizational identity - a story that is a produced by organizational participants with the assistance of analysts, and which stands outside the dyad. The organizational depiction is a narrative about the subject and is derived from participant-observation, qualitative data collection, and the analysis of transference and countertransference dynamics (Diamond, 2003; Diamond and Allcorn, 2003). It emerges out of negotiated collaboration between researchers (analysts, consultants) and organizational participants (clients). I say it is "negotiated" because the analysts are responsible for the method and process, while the 
clients contractually agree to assume the role of research subjects. Yet, it is the case that the organizational diagnosis as presented by the consultants is received by the clients as oedipal law. Clients are often surprised by its directness and absence of defensive camouflage. Nevertheless, as an act of storytelling, the organizational narrative produces a psychological space, an analytic third, for participants' reflectivity and identification.

In this analytic third, workers are able to claim a collective representation (organizational identity), one that is the product of their ongoing, dynamic relational system. The organizational identity then becomes that transitional and potential space from which participants engage their subjectivity, objectivity, and triangulation (Winnicott, 1971; Diamond, 1988, 1993; Britton, 2004).

In psychoanalytically informed organizational change, the analytic third is a critical element of the process of organizational intervention. It is the mental and emotional space created by the confirmation of a collective story of "I-subject," the organizational diagnosis, of organized relationships. And with this confirmed sense of collective self (organization), reflective and facilitated processes for planning, restructuring, resolving conflicts, problem setting and solving take hold. A place is established where co-workers become fellow subjects capable of mutual recognition and self-assertion. In a psychoanalytically informed organizational change effort these processes and concomitant actions, which occur in work groups, are supported by consultants' and leaders' facilitation of a good enough holding environment (containment) for participants' anxieties.

\section{Reflecting on the third}

Organizations are relational, experiential, perceptual, and intellectual systems with an espoused collective mission and task environment. Viewing organizations as identities, which are collectively produced by participants and their leaders, implies the assumption of responsibility and ownership on the part of individuals who perpetuate and reproduce these (relational systems) organizational cultures with their everyday, often automatic and unconscious, routines and actions. From a contemporary psychoanalytic and systems perspective, organizational cultures are the construction of conscious and unconscious dialectical (social and psychological) forces between participants and with other organizational entities. And, while one might argue that these systems evolve and emerge automatically, if not unconsciously, over time, the notion that organizations are social-psychological and dialectical constructions supports the idea that participants reclaim them (as their own creation) by associating their conscious and unconscious actions to the production of manifest and latent dimensions of organizational identity.

The capacity of members to make intellectual and emotional connections with their collective representation of organization (externalized self-system) is 
critical to meaningful and valuable organizational change processes (Diamond, 1984, 1988). The analytic third in organizational change heightens analysts' and participants' awareness both of the organization as a relational system and of their part in its production, destruction, and reproduction. This selfconsciousness and reflectivity enable attention to defensive resistances to insight and change, while enhancing members' capacity to assume responsibility for productive and counter-productive relationships and elements of organization.

\section{Conclusion}

The concept of the analytic third as the location and psychological space for change processes ought to be a principle of contemporary psychoanalytic theories of organizational change. First, the notion of the analytic third assumes that organizations are relational systems, which encourages organizational analysts to attend to the perceptual, intellectual, experiential, and emotional productions that stem from linkages, couplings, and collisions between participants. Thus, as a theory of organization it rests on the object relational psychoanalytic foundation of a two-person (or one might say three-person), rather than one-person, psychology.

Finally, as I have presented it here the notion of the third in psychoanalysis acknowledges that human nature is object-seeking and intersubjective, and that human relations are dialectical and triangulated. Developing the analytic third and the sort of reflexivity inherent to it requires repetition, and it requires as well that the analysts pay attention to counter-transference. This demands heightened self-awareness to the pull toward regression, which is characteristic of projective identification (Ogden's subjugating third) and the clients' unconscious proclivity in the face of anxiety to attempt to control and manipulate consultants. The psychodynamics of projective identification are at the heart of the subjugating third, and in organizational change it occurs frequently, as we saw in the case presented above.

The concept of the analytic third brackets and clarifies the analysts' (consultants') placement of his or her attention in consultation with clients. The notion of the third in psychoanalysis and in psychoanalytically informed organizational consultation locates the triangular space (transitional and potential) in which authentic change and reflectivity are produced. Thus, the role and function of participant observation and the use of one's self as a barometer of relational sentience, is enhanced by our understanding of thirdness. The capacity to interpret self and object relations in the context of groups and organizations is enhanced by the analytic third.

The notion of the analytic third (as self-consciousness) resolves the problem of duality - such as oppression and violence in the grasp of dominantsubmissive dyads, from lovers to leaders and followers in hierarchic structures 
of power and authority (Benjamin, 1988; Diamond and Allcorn, 2004; Minolli and Tricoli, 2004). Owing to the prevalence of unconscious distortion and manipulation in object relations and to (not necessarily pathological) everyday regressive psychodynamic processes of splitting and projective identification, the concept of the analytic third offers perspective in theory and practice.

\section{About the author}

Dr Michael A Diamond is Professor of Public Affairs and Director of the Center for the Study of Organizational Change at the Truman School of Public Affairs at the University of Missouri-Columbia. He was awarded the 1994 Harry Levinson Award for Excellence in Consulting Psychology from the American Psychological Association, the 1999 William T. Kemper Fellow for Excellence in Teaching and the 2005 Faculty-Alumni Award from the University of MissouriColumbia. He is founder and past-president of the International Society for the Psychoanalytic Study of Organizations (ISPSO). His last article "Perversions of Democracy in the Workplace: A Contemporary Psychoanalytic Project" was published in PCS 2006.

\section{Notes}

1 The author wishes to acknowledge the clarification in this instance of one of the anonymous PCS reviewers.

2 This notion of surrender to the emergent third comes closer to what I imagine to be Winnicott's conception of the true and authentic self in contrast to the false and compliant self.

3 You might say that with the concept of the third in relational psychoanalysis $1+1=3$.

4 The third position may remind some of H.S. Sullivan's (1953) technique of counter-projection where the projected image is placed momentarily outside the dyad so that it can be viewed with some degree of psychological distance.

5 Projective identification involves the creation of unconscious narratives (symbolized both verbally and nonverbally) that involve the fantasy of evacuating a part of oneself into another person. This fantasied evacuation serves the purpose of either protecting oneself from the dangers posed by an aspect of oneself, or of safeguarding a part of oneself by depositing it in another person who is experienced as only partially differentiated from oneself (Ogden, 2004, p 187).

6 Bion abstracted the model of the relationship "container-contained" from a particular aspect of projective identification, which afforded further insight into this mechanism. According to this model, the infant projects a part of his psyche, especially his uncontrollable emotions (the contained), into the good breast-container, only to receive them back "detoxified" and in a more tolerable form (Grinberg et al., 1993).

7 What I am referring to here as "an expanding potential space" is the depth of experience, insight, and self-consciousness that comes from a good enough holding environment.

8 This has also been true for the study of organizational change from both cognitive and psychoanalytic perspectives. The notion of organizational learning, double-loop learning, reflective practice, and reflective inquiry represent this trend. In particular, see Argyris and Schon (1978) and Diamond (1993).

9 See Freud's essay on "On the Unconscious" (SE XIV, 161) particularly his discussion of the various meanings of the unconscious and the topographical point of view (Gay P. (ed.) The Freud Reader (1989), pp. 572-584). 


\section{References}

Argyris, C. and Schon, D. (1978). Organizational Learning. Massachusetts: Addison Wesley Publishers.

Aron, L. and Summer Anderson, F. (1998). Relational Perspectives on the Body. Hillsdale, NJ: Analytic Press.

Benjamin, J. (1988). The Bonds of Love. New York: Pantheon.

Benjamin, J. (2004). Beyond Doer and Done to: An Intersubjective View of Thirdness. The Psychoanalytic Quarterly 73 (1), pp. 5-46.

Bion, W.R. (1967). Second Thoughts. London: Karnac Books (reprinted 2003).

Bowlby, J. (1969). Attachment. New York: Basic Books.

Bowlby, J. (1973). Separation: Anxiety and Anger. New York: Basic Books.

Bowlby, J. (1980). Loss: Sadness and Depression. New York: Basic Books.

Britton, R. (2004). Subjectivity, Objectivity, and Triangular Space. The Psychoanalytic Quarterly 73 (1), pp. 47-62.

Cavell, M. (1998). Triangulation, One's Own Mind, and Objectivity. International Journal of Psychoanalysis 55, pp. 349-357.

Diamond, M.A. (1984). Bureaucracy as Externalized Self-System: A View from the Psychological Interior. Administration \& Society 16 (2), pp. 195-214.

Diamond, M.A. (1988). Organizational Identity: A Psychoanalytic Exploration of Organizational Meaning. Administration \& Society 20 (2), pp. 166-190.

Diamond, M.A. (1993). The Unconscious Life of Organizations: Interpreting Organizational Identity. Westport, CT: Greenwood Publishing, Quorum Books.

Diamond, M.A. (2003). Organizational Immersion and Diagnosis: The Work of Harry Levinson. Organisational \& Social Dynamics 3 (1), pp. 1-18.

Diamond, M.A. and Allcorn, S. (2003). The Cornerstone of Psychoanalytic Organizational Analysis: Psychological Reality, Transference, and Counter-Transference in the Workplace. Human Relations 56 (4), pp. 491-514.

Diamond, M.A. and Allcorn, S. (2004). Moral Violence in Organizations: Hierarchic Dominance and the Absence of Potential Space. Organisational o Social Dynamics 4 (1), pp. 22-45.

Diamond, M.A., Allcorn, S. and Stein, H.F. (2004). The Surface of Organizational Boundaries: A View from Psychoanalytic Object Relations Theory. Human Relations 57 (1), pp. 31-53.

Fairbairn, R.D. (1952). An Object Relations Theory of Personality. New York: Basic Books.

Fonagy, P. et al. (1991). Thinking about Thinking: Some Clinical and Theoretical Considerations in the Treatment of a Borderline Patient. International Journal of Psycho-Analysis 72, pp. 1-18.

Fonagy, P. (2001). Attachment Theory and Psychoanalysis. New York: Other Press.

Gay, P. (ed.) (1989). The Freud Reader. New York: W.W. Norton \& Co.

Gerson, S. (2004). The Relational Unconscious: A Core Element of Intersubjectivity, Thirdness, and Clinical Process. The Psychoanalytic Quarterly 73 (1), pp. 63-98.

Ghent, E. (1990). Masochism, Submission, Surrender. Contemporary Psychoanalysis 26, pp. 169-211. 
Green, A. (2004). Thirdness and Psychoanalytic Concepts. The Psychoanalytic Quarterly 73 (1), pp. 99-136.

Grinberg, L., Sor, D. and Tabak de Bianchedi, E. (1993). New Introduction to the Work of Bion (revised edition) New Jersey: Jason Aronson, Inc.

Guntrip, H. (1969). Schizoid Phenomena, Object Relations and the Self. New York: International Universities Press.

Hegel, G.W.F. (1807). The Phenomenology of Mind. Baille, J.B. (trans.) London: George Allen \& Unwin, New York: Humanities Press.

Klein, M. (1986). The Selected Melanie Klein. Mitchell, J. (ed.) New York: Free Press.

Klein, M. and Riviere, J. (1964). Love, Hate and Reparation. New York: W.W. Norton \& Co.

Lacan, J. (1975). The Seminar of Jacques Lacan, Book I, 1953-1954. Forrester, J. (trans.) New York: W.W. Norton \& Co. (reprinted 1991).

Mills, J. (2000). Hegel on Projective Identification: Implications for Klein, Bion, and Beyond. The Psychoanalytic Review 87 (6), pp. 841-874.

Minolli, M. and Tricoli, M.L. (2004). Solving the Problems of Duality: The Third and SelfConsciousness. The Psychoanalytic Quarterly 73 (1), pp. 137-166.

Mitchell, S.A. (1988). Relational Concepts in Psychoanalysis: An Integration. Cambridge, MA: Harvard University Press.

Mitchell, S.A. and Aron, L. (1999). Relational Psychoanalysis, preface XV. New York: The Analytic Press.

Ogden, T. (1994). Subjects of Analysis. New Jersey: Jason Aronson, Inc.

Ogden, T. (2004). The Analytic Third: Implications for Psychoanalytic Theory and Technique. The Psychoanalytic Quarterly 73 (1), pp. 167-196.

Pierce, C. (1972). Charles S. Pierce: The Essential Writings. E.C. Moore (ed.) New York: Harper \& Row.

Searle, J.R. (1995). The Mystery of Consciousness: Part II. The New York Review of Books 42 (18), pp. 54-61.

Stern, D. (1985). The Interpersonal World of the Infant. New York: Basic Books.

Sullivan, H.S. (1953). The Interpersonal Theory of Psychiatry. New York: W.W. Norton \& Co.

Winnicott, D.W. (1965). The Maturational Processes and the Facilitating Environment. New York: International Universities Press.

Winnicott, D.W. (1971). Playing \& Reality. London: Tavistock Publications.

Zweibel, R. (2004). The Third Position: Reflections about the Internal Analytic Working Process. The Psychoanalytic Quarterly 73 (1), pp. 215-265. 